Cahiers $d u$ MONDE RUSSE

\section{Cahiers du monde russe}

Russie - Empire russe - Union soviétique et États indépendants

$60 / 4 \mid 2019$

Varia

\title{
Michel AUCOUTURIER, Essais sur Boris Pasternak. Édité par Catherine Depretto
}

\section{Caroline Bérenger}

\section{OpenEdition}

\section{Journals}

Édition électronique

URL : https://journals.openedition.org/monderusse/11622

DOI : $10.4000 /$ monderusse. 11622

ISSN : 1777-5388

\section{Éditeur}

Éditions de l'EHESS

\section{Édition imprimée}

Date de publication : 1 octobre 2019

Pagination : 885-887

ISBN : 978-2-7132-2797-4

ISSN : $1252-6576$

Référence électronique

Caroline Bérenger, «Michel AUCOUTURIER, Essais sur Boris Pasternak. Édité par Catherine Depretto », Cahiers du monde russe [En ligne], 60/4 | 2019, mis en ligne le 01 octobre 2019, consulté le 05 janvier 2023. URL : http://journals.openedition.org/monderusse/11622 ; DOI : https://doi.org/10.4000/ monderusse. 11622 
Michel AUCOUTURIER

Essais sur Boris Pasternak

Édité par Catherine Depretto

Paris : Institut d'Études slaves, 2019, 253 p.

Ce volume réunit les travaux que Michel Aucouturier (1933-2017) a menés sur l'œuvre de Boris Pasternak (1890-1960) pendant plus d'un demi-siècle. Catherine 
Depretto l'a conçu comme un parcours philologique au sens plein du terme, restituant la cohérence d'une méthode, la vigueur d'une pensée en évolution dans le contexte de la slavistique française. C'est aussi un témoignage de ce qu'est la recherche en sciences humaines, la fréquentation du texte littéraire en tant que pratique des humanités. C'est enfin le portrait d'un esprit scientifique remarquable, dont le ressort secret était l'admiration qu'il vouait au poète.

Chaque étude part d'une intuition que l'auteur s'emploie à démontrer par des micro-analyses ciblées. Dans «О трех хлебниковских стихотворениях [Trois poèmes khlebnikoviens] de Pasternak (2009), il examine les traces de l'expérimentation futuriste à partir d'un décalque d'un texte sur l'autre. Il traduit le poème « Я тоже любил, и дыхание... » [J'ai aimé, moi aussi...] et repère son point de bascule de l'instant vers l'éternité (2008) en décrivant ses différents niveaux, prosodique, lexical, stylistique, sur le modèle des études quantitatives de Mihaïl Gasparov. À cet égard, «L'image dans la poésie de Pasternak » (1961) est un article fondateur de sa virtuosité à saisir l'indicible. Michel Aucouturier interroge son objet en imitant ses propriétés. Le poème est " une unité émotionnelle ", " une expérience synthétique de la réalité ». Le commentaire se fraye un chemin dans l'enchevêtrement de la langue poétique pour déplier sémantiquement ses propriétés expressives. Cette homogénéité entre le poème et son interprétation aboutit à ce que l'on pourrait appeler une contemplation mise en algèbre. C'est ainsi qu'une déclaration de Pasternak : «ne plus écrire avec les mains, écrire avec les pieds » est convertie en théorème : «Faire de l'œuvre un acte inséré dans la trame de la vie et non plus une inutile représentation de la réalité ». " Toute l'évolution de la prose de Pasternak tend vers la réalisation de ce roman-acte qui est l'accomplissement de sa vie ». L'auteur emprunte les traits organiques de la poétique de Pasternak pour construire son raisonnement.

Son attention minutieuse au texte se combine à une vision synthétique de l'œuvre. Il montre que la métonymie, principale figure de style de la poésie de Pasternak, fonctionne de façon transversale. Le principe de contiguïté agit dans la langue mais détermine aussi son rapport au monde : la réceptivité du sujet lyrique, sa fusion avec la nature, les qualités propres au " héros métonyme ». L'article sur l'antimodernisme de Pasternak (2005) est une méditation sur la modernité littéraire. Des débuts futuristes du poète à la rupture esthétique de 1936, Michel Aucouturier montre que ce tournant n'est pas une intériorisation des contraintes du réalisme socialiste, mais une dissidence idéologique. La fin du modernisme pour Pasternak est dictée par sa vocation et sa conscience historique. Le passage de la poésie à la prose puis le retour au poème qui s'accomplit dans Le Docteur Jivago est analysé dans le cadre de l'évolution littéraire : les vers du héros qui achèvent le roman symbolisent « la source vive de la création poétique, à laquelle [1]a prose n'a jamais cessé de s'alimenter » (1995). Dans « Une clé pour sauf-conduit » (1979), Michel Aucouturier examine le rapport conflictuel du poète au temps, «prisonnier de son époque » mais « otage de l'éternité ». Quant à la place de la philosophie chez Pasternak, il affirme au contraire de Lazar Fleichman, qu'elle ne fait pas système, 
mais reste subordonnée à l'expression lyrique et que c'est finalement son abandon par le poète qui fait sens.

La question du poétique et du politique s'inscrit dans une réflexion sur les révolutions en France et en Russie (1986, 1989, 1993). L'auteur met en évidence la polysémie du mot révolution chez Pasternak, qui oscille entre le mythe personnel et le phénomène cosmique, tour à tour synonyme d'enfance, d'amour, de femme ou de poésie. L'ambiguïté sémantique éclaire la position contradictoire du poète par rapport au fait historique. Elle explique aussi son immunité face à Stalin. Sa « haute maladie » est une fidélité à sa nature profonde sans compromis possible, qui le garde de toute compromission. " Pasternak offre l'exemple à peu près unique d'un écrivain célèbre, mais ignoré des autorités, vivant en marge de l'institution littéraire soviétique ».

Critique et traducteur, Michel Aucouturier fut aussi le passeur de l'œuvre de Pasternak en France, grâce à la connaissance qu'il en avait, de l'intérieur et de l'extérieur, dans un dialogue continu avec les intellectuels russes, Fleichman, Sinjavskij, Gasparov, etc. À la lecture de ce volume, on mesure la force de sa pensée théorique et ce qu'elle doit à l'école formaliste. Michel Aucouturier apparaît finalement comme son héritier en ligne directe. Fidèle à l'intention première de ses fondateurs, Šklovskij, Jakobson ou Tynianov, il a pratiqué la littérature comme une science. Il nous offre des leçons de poétique dans la grande tradition russe et française. Catherine Depretto évoque son « intelligence du texte », « son approche spontanée et savante ». Il construit une argumentation dense et précise, limite à dessein son objectif pour mieux l'atteindre. Ses démonstrations rigoureuses sont tempérées par la nuance et la finesse. Il ne force pas le trait, ce serait pour lui l'indice d'une faiblesse. Il garde une familiarité distante avec son objet en toutes circonstances. Son intégrité émotionnelle et intellectuelle ne verrouille jamais sa pensée malgré les contraintes qu'elle lui impose, le dernier mot est laissé au texte poétique.

Ce qui donne à cet essai son inspiration, c'est le lien qui unissait les deux hommes. Michel Aucouturier a rencontré Boris Pasternak, il l'a connu et aimé comme personne et comme poète. Catherine Depretto évoque « un coup de foudre », qui a touché les racines de son être. Elle souligne la difficulté à faire de cette expérience intime un objet d'étude. C'est sans doute ce qui explique la réserve de Michel Aucouturier, sa délicatesse, toujours perceptible dans ses travaux, c'est aussi ce qui lui permet d'apporter un éclairage subtil sur l'œuvre. Il faudrait éditer sa correspondance avec Boris Pasternak, ainsi que ses poèmes, des documents qui appartiennent à la sphère privée, mais ont joué un rôle essentiel dans le travail du slaviste.

\section{Caroline Bérenger}

Université de Caen Basse-Normandie 